Indian J. Anim. HIth. (2018), 57(2) : 219-224

Short Communication

\title{
SEMEN CHARACTERISTICS IN YOUNG AND ADULT SURTI BUCK
}

\author{
V. B. ATARA*, C. F. ChAudhari, U. V. RAMANi, M. M. ChaUdhary \\ D. K. PATEL, Y. R. PATEL AND N. G. PATEL \\ Department of Veterinary Gynaecology and Obstetrics, Veterinary College \\ Navsari Agricultural University, Navsari, Gujarat-396 450, India
}

\begin{abstract}
Present study was conducted to study the effect of age on semen parameters in Surti buck. Age was significantly influenced on majority of the semen parameters in Surti bucks. Adult bucks significantly $(\mathbf{P}<0.01)$ performed better in terms of semen quantitative parameters viz., semen density $(3.91+0.03 \mathrm{vs}$ $3.79 \pm 0.03)$, volume $(1.01 \pm 0.03$ vs $0.86 \pm 0.03 \mathrm{~mL})$, sperm concentration $(2564.22 \pm 87.27$ vs $1978.13 \pm 60.79$ $\mathrm{million} / \mathrm{mL})$, total sperm count $(2483.83 \pm 115.22$ vs $1546.93 \pm 62.96$ million) and semen index (1737.19 $\pm 78.10 v s$ 1104.39 \pm 47.29 million). However, semen qualitative parameters $v i z$, initial progressive motility $(93.75 \pm 0.22$ vs $93.72 \pm 0.21 \%)$, live sperm count $(75.36 \pm 0.93$ vs $75.93 \pm 0.74 \%)$, sperms with physically intact plasma membrane $(\mathbf{8 5 . 2 8} \pm 0.27$ vs $85.31 \pm 0.19 \%)$, progressive motility at various intervals and morphologically normal spermatozoa were at par in adult as well as in young Surti bucks.
\end{abstract}

Key words: AV method, Semen ejaculates, Semen parameters, Surti buck

The conception rate is chiefly depends upon quality of the semen determined by various qualitative and quantitative semen parameters. These semen parameters are influenced by age of the bucks. Surti goat is a medium sized dual purpose breed, confined to small towns and cities situated on the western coastal belt of the South Gujarat. Reports are available on effect of age on semen parameters in different breed of goats; however, no such report is available on Surti bucks. Hence, the experiment was conducted to study the influence of age on Surti buck semen parameters.

Total nine apparently healthy Surti bucks maintained under All India Coordinated Research Project (AICRP) on Goat,

*Corresponding Author 
Livestock Research Station, Navsari Agricultural University, Navsari were selected and divided in to two groups based on their age viz., adult bucks (22 to 26 months, $n=4$ ) and young bucks (14 to 15 months, $n=5)$. The semen was collected regularly by artificial vagina method twice a week from each buck up to 16 weeks (160 ejaculates from young bucks and 128 ejaculates from adult bucks). The samples were evaluated by standard laboratory procedures available in literature. Additionally, total sperm count per ejaculate was calculated by multiplying sperm concentration/mL by the volume of the ejaculate. While, semen index $\left(\times 10^{6}\right)$ was calculated by multiplying semen volume, sperm concentration $/ \mathrm{mL}$, live sperm count and progressive motility (Barkawi et al., 2006). Moreover, the motility degeneration rate at different intervals was calculated as per the formula given by Campos et al. (2004). The data pertaining to various aspects were suitably tabulated and analyzed using IBM SPSS statistics (version 20) software by t-test.

The influence of age on various semen parameters is presented in Table 1. In present experiment, mean density was significantly $(\mathrm{P}<0.01)$ higher in adult $(3.91 \pm 0.03)$ bucks compared to young $(3.79 \pm 0.03)$ bucks. Similarly, the mean semen volume $(\mathrm{mL})$ was significantly $(\mathrm{P}<0.01)$ higher in adult $(1.01 \pm 0.03)$ than young $(0.86 \pm 0.03)$ bucks which was comparable with Mia et al. (2013). While, Parmar et al. (2011) obtained similar amount of semen volume $(0.84 \pm 0.02 \mathrm{~mL})$ in 12-18 months old Mehsana bucks, which was at par with present value of volume $(0.86 \pm 0.03 \mathrm{~mL})$ in young bucks. Compared to present study, Thakur et al. (2005) obtained quit low amount of semen volume $(0.47 \pm 0.03 \mathrm{~mL})$ from 1.5 to 2.5 years old Chegu Pashmina bucks.

The mass activity was non-significantly differed between two groups $(4.73 \pm 0.04 v s$ $4.66 \pm 0.04)$ in present study which was in accordance with Mia et al. (2013), while, Gogoi et al. (2008) reported gradually increased mass activity with increased age. Further, the observed value of mass activity in present study was almost similar to those reported by Thakur et al. (2005) and quit higher than reported by Suyadi (2012), Kalyani et al. (2015) and Siddiqua et al. (2016).

The average initial progressive motility (\%) was non-significantly differed between young $(93.72 \pm 0.21)$ and adult $(93.75 \pm 0.22)$ bucks. Akpa et al. (2013) also observed non-significant difference in motility between different age groups of Red Soketo bucks. Whereas, the initial motility observed in present investigation was comparatively higher than reported by Apu et al. (2008), Kerketta et al. (2014), Kalyani et al. (2015) and Siddiqua et al. (2016), while, Gogoi et al. (2008) recorded gradually increased overall initial sperm 
Table 1. Semen parameters (Mean+SE) in Surti bucks

\begin{tabular}{lllll}
\hline Semen Parameters & Young $(\mathbf{n = 1 6 0})$ & Adult $(\mathbf{n = 1 2 8})$ & t value & P value \\
\hline Density & $3.79 \pm 0.03$ & $3.91 \pm 0.03$ & $2.57^{* *}$ & 0.01 \\
Volume (mL) & $0.86 \pm 0.03$ & $1.01 \pm 0.03$ & $3.56^{* *}$ & 0.00 \\
Mass activity & $4.66 \pm 0.04$ & $4.73 \pm 0.04$ & $1.24^{\mathrm{NS}}$ & 0.22 \\
Initial progressive motility (\%) & $93.72 \pm 0.21$ & $93.75 \pm 0.22$ & $0.10^{\mathrm{NS}}$ & 0.92 \\
Sperm concentration (Million/mL) & $1978.13 \pm 60.79$ & $2564.22 \pm 87.27$ & $5.66^{* *}$ & 0.00 \\
Total sperm count (Million) & $1546.93 \pm 62.96$ & $2483.83 \pm 115.22$ & $7.51^{* *}$ & 0.00 \\
Live sperm (\%) & $75.93 \pm 0.74$ & $75.36 \pm 0.93$ & $-0.48^{\mathrm{NS}}$ & 0.63 \\
HOS Reacted sperm (\%) & $85.31 \pm 0.19$ & $85.28 \pm 0.27$ & $0.08^{\mathrm{NS}}$ & 0.94 \\
Semen Index & $1104.39 \pm 47.29$ & $1737.19 \pm 78.10$ & $7.23^{* *}$ & 0.00 \\
\hline
\end{tabular}

${ }^{{ }^{* *} \text { Significant at } \mathrm{P}<0.01 ; \mathrm{NS} \text { : Non-significant }}$

Table 2. Progressive motility (\%) and motility degeneration rate (MDR) at $30 \mathrm{~min}$. intervals (Mean+SE) in Surti bucks

\begin{tabular}{lllll}
\hline Time Interval & Young $(\mathbf{n = 1 6 0})$ & Adult $(\mathbf{n = 1 2 8})$ & t value & P value \\
\hline Progressive motility $(\%)$ & & & & \\
\hline 30 min. & $87.41 \pm 0.35$ & $87.54 \pm 0.35$ & $0.27^{\mathrm{NS}}$ & 0.79 \\
$60 \mathrm{~min}$. & $80.28 \pm 0.43$ & $80.98 \pm 0.48$ & $1.08^{\mathrm{NS}}$ & 0.28 \\
$90 \mathrm{~min}$. & $73.22 \pm 0.57$ & $74.61 \pm 0.57$ & $1.70^{\mathrm{NS}}$ & 0.09 \\
$120 \mathrm{~min}$. & $65.97 \pm 0.67$ & $66.88 \pm 0.79$ & $0.88^{\mathrm{NS}}$ & 0.38 \\
\hline Motility degeneration rate $\mathbf{\%})$ & & & \\
\hline 30 min. & $6.77 \pm 0.25$ & $6.65 \pm 0.24$ & $-0.35^{\mathrm{NS}}$ & 0.73 \\
60 min. & $14.39 \pm 0.36$ & $13.67 \pm 0.42$ & $-1.32^{\mathrm{NS}}$ & 0.19 \\
90 min. & $21.96 \pm 0.54$ & $20.48 \pm 0.53$ & $-1.94^{*}$ & 0.05 \\
120 min. & $29.71 \pm 0.67$ & $28.77 \pm 0.79$ & $-0.92^{\mathrm{NS}}$ & 0.36 \\
\hline
\end{tabular}

"Significant at $\mathrm{P}<0.05$, NS: Non-significant

Table 3. Sperm morphological parameters (Mean+SE) in Surti bucks

\begin{tabular}{lllll}
\hline Parameters $(\%)$ & Young $(\mathbf{m = 1 6 0})$ & Adult $(\mathbf{n = 1 2 8})$ & t value & P value \\
\hline Normal sperm & $97.43 \pm 0.12$ & $97.41 \pm 0.19$ & $-0.08^{\mathrm{NS}}$ & 0.94 \\
Head abnormality & $0.41 \pm 0.05$ & $0.39 \pm 0.08$ & $-0.17^{\mathrm{NS}}$ & 0.86 \\
Mid-piece abnormality & $0.96 \pm 0.10$ & $0.83 \pm 0.11$ & $-0.90^{\mathrm{NS}}$ & 0.37 \\
Tail abnormality & $0.78 \pm 0.09$ & $0.95 \pm 0.16$ & $0.95^{\mathrm{NS}}$ & 0.34 \\
Cytoplasmic droplets & $0.06 \pm 0.03$ & $0.03 \pm 0.02$ & $-0.82^{\mathrm{NS}}$ & 0.41 \\
Total abnormality & $2.57 \pm 0.12$ & $2.59 \pm 0.19$ & $-0.08^{\mathrm{NS}}$ & 0.94 \\
\hline
\end{tabular}

NS: Non-significant 
motility with increased in the age of bucks.

The average sperm concentration (million/ $\mathrm{mL}$ ) estimated by haemocytometer method was significantly $(\mathrm{P}<0.01)$ higher in adult (2564.22 \pm 87.27$)$ bucks than young $(1978.13 \pm 60.79)$ bucks which was in accordance with Suyadi (2012) and Mia et al. (2013). However, the mean values were lower than the observation of Jadav et al. (2008), Parmar et al. (2011) and Kerketta et al. (2014). The mean total sperm count in present experiment was $1546.93 \pm 62.96$ and $2483.83 \pm 115.22$ millions per millimeter in young and adult bucks, respectively. The difference between them was highly $(\mathrm{P}<0.01)$ significant.

The average live sperm count (\%) was $75.93 \pm 0.74$ in young and $75.36 \pm 0.93$ in adult bucks. Gogoi et al. (2008) observed increased live sperm count with increased in the age of bucks, while, Thakur et al. (2005) obtained lower live sperm count than the present findings. Almost similar mean HOS reacted spermatozoa $(\%)$ were observed in young $(85.31 \pm 0.19)$ and adult $(85.28 \pm 0.27)$ bucks which was in accordance with the reporting of Kalyani et al. (2015).

The semen index was significantly $(\mathrm{P}<0.01)$ higher in adult $(1737.19 \pm 78.10)$ bucks compared to young (1104.39 \pm 47.29$)$ bucks. The average progressive motility (\%) at 30 min, $60 \mathrm{~min}, 90 \mathrm{~min}$ and $120 \mathrm{~min}$ was nonsignificantly higher in adult $(87.54 \pm 0.35$, $80.98 \pm 0.48,74.61 \pm 0.57$ and $66.88 \pm 0.79)$ bucks than young $(87.41 \pm 0.35,80.28 \pm 0.43$, $73.22 \pm 0.57$ and $65.97 \pm 0.67)$ bucks, respectively (Table 2 ). While, average motility degeneration rate $(\%)$ at $30 \mathrm{~min}$, $60 \mathrm{~min}$ and $120 \mathrm{~min}$ was non-significantly higher in young $(6.77 \pm 0.25,14.39 \pm 0.36$ and $29.71 \pm 0.67)$ bucks than adult $(6.65 \pm 0.24,13.67 \pm 0.42$ and $28.77 \pm 0.79)$ bucks, respectively. It was significantly $(\mathrm{P}<0.05)$ higher at $90 \mathrm{~min}$ in young (21.96 \pm 0.54$)$ bucks compared to adult (20.48+0.53) bucks.

The mean total sperm abnormalities (\%) differed non-significantly between young $(2.57 \pm 0.12)$ and adult $(2.59 \pm 0.19)$ bucks (Table 3). Similarly, Suyadi (2012) also observed non-significant difference in abnormal spermatozoa between different age groups of bucks, while, Jadav et al. (2008), Parmar et al. (2011) and Kalyani et al. (2015) observed higher percentage of total abnormalities compared to present study.

From the present experiment it was concluded that as the adult Surti bucks significantly performed better compared to young bucks in terms of semen quantitative parameters they should be preferred over young bucks for breeding purpose.

\section{ACKNOWLEDGEMENTS}

The authors are highly thankful to the ICAR-AICRP on goat improvement (Surti field unit), staff of LRS and Department of ARGO; Veterinary collage, NAU, Navsari for providing necessary help for the study. 


\section{REFERENCES}

Akpa GN, Ambali AL and Suleiman IO, 2013. Body conformation, testicular and semen characteristics as influenced by age, hair type and body condition of Red Sokoto goat. New York Sci J, 16: 44-58

Apu AS, Husain SS, Khandoker MAMY, Rahman AHMS and Notter DR, 2008. Investigation on seminal attributes and fertility of Black Bengal goat. Bangladesh J Ani Sci, 37: $17-24$

Barkawi AH, Elsayed EH, Ashour G and Shehata E, 2006. Seasonal changes in semen characteristics, hormonal profiles and testicular activity in Zaraibi goats. Small Ruminant Res, 66: 209-213

Campos ACN, Nunes JF, Monteiro AWU, de Figueiredo EL and Pinheiro JHT et al., 2004. Viability of washed and unwashed goat sperm diluted in coconut water, cooled and storage at $4^{\circ} \mathrm{C}$. Rev Bras Cien Vet, 11: 178-182

Gogoi C, Deka BC, Biswas RK, Sarma BC and Nath KC et al., 2008. Semen characteristics and scrotal and testicular dimensions of crossbred bucks. Indian Vet J, 85: 454-455

Jadav PV, Shah RG, Sarvaiya NP and Patel DM, 2008. Studies on physical characteristics of semen of Surti bucks. Indian J Field Vet, 4: 20-24

Kalyani R, Gojen SL and Bidhan S, 2015. Cryopreservation of Black Bengal buck semen by Tris-based extenders containing different levels of eggyolk. Ann Vet Anim Sci, 2: 47-54

Kerketta S, Singh M, Patel BHM, Verma M and Prasad JK et al., 2014. Study on buck's mating behaviour, libido score and semen biology in local goat of Rohilkhand region, India. Indian J Anim Res, 48: 491-495

Mia MM, Khandoker MAMY, Husain SS, Faruque MO and Notter D et al., 2013. Genetic and phenotypic parameters for semen characteristics and their relationship with scrotal circumference in Black Bengal bucks. Iran J Appl Anim Sci, 3: 709717

Parmar VR, Suthar BN, Nakhashi HC, Parikh SS and Chauhan PM, 2011. Study on physical characteristics of Mehsana buck semen. Indian J Anim Res, 45: 207-210

Siddiqua A, Islam N, Rahman M, Khandoker Y and Mahfuzul Bari AS, 2016. Evaluation of semen quality of Black Bengal goat in Bangladesh. Int $\mathbf{J}$ Natural Soc Sci, 3: 05-09 
Suyadi S. 2012. Sexual behaviour and semen characteristics of young male Boer goats in tropical condition: A case in Indonesia. Int J Biol Biomol Agri Food Biotech Eng, 6: 388-391
Thakur YP, Singh M and Jasial S, 2005. Semen production and freezability attributes of Chegu Pashmina bucks. Indian J of Anim Sci, 75: 1165-1167

Article received on 08.06.2018 and accepted for publication on 09.09.2018 